\title{
Análise dos determinantes no grau de evidenciação do risco de crédito em centrais de cooperativas de crédito
}

\section{Analysis of determinants in the degree of disclosure of credit risk in credit unions}

\author{
Thais Brandalize ${ }^{\mathrm{I}}$, Leonardo Flach ${ }^{\mathrm{II}}$, Jonatas Dutra Sallaberry ${ }^{\text {III }}$ \\ ' Universidade Federal de Santa Catarina, SC. thaibrandalize3@gmail.comt \\ "Universidade Federal de Santa Catarina, SC. leonardo.flach@gmail.com \\ II' Universidade Federal de Santa Catarina, SC. jonatas.sallaberry@hotmail.com
}

\section{RESUMO}

A transparência dos dados contábeis e financeiros amplia a possibilidade do usuário tomar decisões corretas, minimizando possíveis perdas. Diante disso, buscou-se analisar os determinantes que impactam no grau de evidenciação do gerenciamento de risco de crédito nas centrais cooperativas de crédito. A amostra é constituída pelas Centrais de Cooperativas de Crédito, sendo que o Disclosure do Risco de Crédito (DRC) foi coletado conforme método aplicado por Dantas et al. (2010), enquanto as variáveis financeiras do Banco Central do Brasil. Para análise foram formuladas hipóteses, analisados com estatística descritiva e regressão de dados em painel. A análise dos resultados apresenta contribuições teóricas e empíricas. O grau de DRC foi inferior ao esperado, explicado pelo tamanho e o índice de imobilização, todavia, a rentabilidade não foi significativa para determinar o grau de divulgação, ou seja, níveis de evidenciação não estão relacionados ao desempenho econômicofinanceiro nas cooperativas de crédito.

Palavras-chave: evidenciação, risco de crédito, cooperativa de crédito.

\section{ABSTRACT}

The present research is predominantly qualitative with exploratory characteristics and, through interviews guided by a script of semistructured questions. The interviews were analyzed from three dimensions: implementation, organizational and territorial. It is evident in the research findings that 
there are bureaucratic delays in the MMP that make it difficult for the rural extension system entity to implement the public call instruments - pre-diagnosis, diagnosis, action plan and improvement. The results of the organizational dimension are distinct among cooperatives, and the more structured have made better use of MMP. These results are reiterated in the analysis of the territorial dimension where these elements reflect the dynamism of cooperativism in certain municipalities and can explain the proactivity of the organizations in response to the MMP stimuli.

Keywords: cooperatives; public policy; rural development.

\section{INTRODUÇÃO}

Em 1988, o Comitê de Supervisão Bancária da Basileia (CBBS), fundado pelo Banco de Compensações Internacionais, divulgou o acordo de Capital da Basileia. Em 2004, houve uma evolução desse documento que ficou conhecida como Basileia II, este acordo possui três pilares: capital, revisão pela supervisão e disciplina do mercado. Já em 2011, houve um aprimoramento do gerenciamento de risco, conhecido como Basileia III.

No Brasil, as Instituições Financeiras Bancárias são parte do Sistema Financeiro Nacional e são regulamentadas pelo Banco Central do Brasil (BCB). Estas possuem como obrigatoriedade a divulgação do Relatório Financeiro referente ao gerenciamento de risco, tal ato está disposto na Resolução 4.557/2017, que está pautada diretamente nos Acordos da Basileia e foi elaborada pelo Conselho Monetário Nacional (CMN).

O segmento de cooperativas de crédito tem aumentou significativamente na última década $(B C B, 2019)$. Quantidade significativa de cooperativas de crédito prestam os mesmos serviços financeiros a seus cooperados (PORFIRIO; FERNANDES; DANTAS, 2019), além de possuírem uma função social relevante na inclusão e disponibilidade de serviços financeiros em determinadas regiões. Além da relevância do recorte amostral, a escolha das cooperativas de crédito se dá também pelo fato de que as cooperativas de crédito que não possuem obrigatoriedade em tal divulgação. 
A norma financeira define risco em função do efeito das incertezas nos objetivos da organização, que podem ser positivos (oportunidades) ou negativos (ameaças) (BANCO CENTRAL DO BRASIL [BCB], 2019). Assim, a gestão de riscos seria o conjunto de ações coordenadas que buscam garantir que os objetivos sejam perseguidos dentro de limites aceitáveis. Os riscos foram divididos em de origem financeira (mercado, crédito e liquidez). Como a legislação está voltada principalmente para as instituições financeiras bancárias, revela-se o questionamento sobre qual o grau de aderência das cooperativas de crédito com a divulgação desses riscos, e quais são seus determinantes.

Todos os riscos ameaçam a organização, todavia o risco de crédito reveste-se de especial relevância para instituições financeiras por conta de tratar-se de recursos necessários ao cumprimento de suas obrigações além de ser o escopo do negócio emprestar e receber recursos. As instituições financeiras dependem de receber os créditos concedidos a terceiros para fazer frente as suas obrigações; o não recebimento pode tornar a entidade insolvente e sem capacidade de pagar correntistas, cooperados e outras instituições financeiras - causar um risco sistêmico se contagiar outras instituições financeiras.

O gerenciamento consiste no aprimoramento das decisões de concessão de crédito, podendo contribuir para a diminuição da inadimplência do sistema e do spread bancário (Francisco, Amaral, \& Bertucci, 2012). A cooperativa de crédito quando divulga como seus créditos estão estruturados e o seu risco, permite que o mercado financeiro possa tomar a decisão mais adequada na transação de instrumentos financeiros. Diante disso, o objetivo da presente pesquisa será verificar o grau de aderência das cooperativas de crédito ao disclosure de riscos de crédito e identificar seus determinantes.

O risco de crédito é relevante porque a liquidez impacta diretamente no ativo da Entidade em questão que possui como principal atividade o financiamento, 
portanto é fundamental para a solvência da entidade. Além disso, o crédito é uma variável macroeconômica e sua restrição em maior escala pode causar impactos macroeconômicos. Para analisar o exposto, foram coletadas amostras das Centrais do Sistema de Cooperativas de Crédito, no período de 2015 a 2018, que divulgaram o relatório referente ao gerenciamento de risco.

O adequado gerenciamento torna-se mais relevante à medida que o crédito cooperativo ganha mais espaço e, de certa forma, entra em concorrência com as instituições financeiras públicas e privadas. Evidências empíricas sinalizam requisitos de crédito mais brandos em períodos de expansão tanto em captação como em garantias, mas em períodos de crise os mutuários fazem empréstimos bancários mais arriscados, sem garantias (IIMENEZ; SALAS; SAURINA, 2006).

Segundo Savio e Basso (2019), os bancos tradicionais vêm obtendo resultados financeiros significativos e agressivamente têm buscado aumentar sua participação de mercado. O cooperativismo seria uma alternativa de modelo econômico equilibrando a relação entre econômico e social com princípios e valores menos impessoais (SAVIO; BASSO, 2019), todavia a equalização entre receitas e despesas de cooperativas de crédito também precisa ser mantida, e para isso faz-se necessário que as cooperativas gerenciem e evidenciem seus riscos de forma adequada em prol da sua saúde financeira.

\section{REFERENCIAL TEÓRICO}

As instituições financeiras cooperativas possuem por princípio a melhor alocação de recursos entre as partes que possuem recurso excedente e aquelas que precisam de recursos. Assim, elas tomam recursos de terceiros mediante remuneração para posteriormente devolver, a instituição financeira escritura na sua contabilidade um crédito em favor daquele emprestador e uma obrigação para com 
terceiros (NIYAMA; GOMES, 2002). As obrigações afetam a estrutura de capital da entidade, no que tange aos limites e exigências de capital (NIEDERAUER et al., 2018).

De outro lado, as instituições financeiras cooperativas emprestam recursos, mediante remuneração para seus cooperados com objetivo de receber posteriormente. Esses cooperados tomadores de recursos passam a possuir na sua contabilidade um crédito em benefício da cooperativa. A esse conjunto de cooperados que possuem obrigações com a cooperativa que é atribuído o 'risco de crédito' de uma cooperativa.

Essa relação da cooperativa de crédito com seus stakeholders é ainda mais complexa do que numa instituição financeira tradicional, pois na cooperativa de crédito os seus cooperados são fornecedores, clientes e associados "proprietários" ao mesmo tempo (MACHINSKI; MOREIRA; SILVA, 2019). Ela não deixa de possuir uma face de confiança entre as partes (SILVA; FORGIARINI; ALVES, 2019), no entanto ela precisa possuir seus contratos e garantias de segurança na cooperativa, sem prejuízo da adequada contabilização. Seguindo o processo de escrituração regulamentar, cada recurso que a cooperativa tem a receber é contabilizado, todavia no segmento financeiro, ele precisa ser classificado de acordo com critérios de liquidez, ou seja, por ordem e probabilidade de recebimento.

Por isso se torna ainda mais relevante a discussão do risco do não recebimento, porque afeta a contabilização, que por sua vez gera indicadores que afetam a capacidade de recebimento dos recursos, tornando objeto de regulamentação dos órgãos estatais e de análise para investidores e acadêmicos. No presente referencial, optou-se por abordar o referencial legal que normatiza a evidenciação dos riscos de crédito e as hipóteses de pesquisa que se pretende analisar nos resultados da pesquisa. 
2.1 Evolução do Acordo de Basileia I, II e III

A organização Bank for International Settlements (BIS) estimula a colaboração entre Instituições Bancárias, com objetivo de manter a estabilidade financeira e monetária (CUNHA, 2014). Ligado ao BIS surgiu o Comitê de Supervisão Bancária da Basileia (Basel Committe on Banking Supervision - BCBS) que em 1988, na cidade de Basileia, situada na Suíça, instituiu um acordo sobre a constituição de determinações mínimas para a constituição de capital bancário, como prevenção contra o risco de crédito (CUNHA, 2014). No ano de 2004, divulgou o Acordo de Capital da Basileia ou Basileia II, com objetivo de novas medidas preventivas referentes aos riscos bancários, essa evolução foi baseada em três pilares principais.

O primeiro pilar refere-se aos critérios usados para definição do capital mínimo para a gestão dos riscos de crédito, mercado e operacional. Já o segundo relaciona os princípios que devem ser considerados por parte dos supervisores das entidades para que as práticas da gestão de risco sejam constantemente monitoradas, revisadas e aprimoradas (CUNHA, 2014). Enquanto o terceiro incentiva a disciplina do mercado, onde se requer a divulgação dos relatórios financeiros sobre os riscos presumidos pelos Bancos para conhecimento dos sócios, fornecedores e demais interessados, como os cooperados.

Em 2006, houve avanços nas discussões pelo BCBS referente aos riscos. Novas recomendações surgiram, como a carteira de negociação, testes de sensibilidade ao risco e aspectos sobre as inovações financeiras (TORRES; GALDI, 2013). Já em 2009, após a crise financeira global, segundo O BCB "houver novas alterações, com destaque para exigência de capital para o risco do mercado e apreçamento de instrumentos líquidos financeiros".

Publicado em 2010 e atualizado em 2011, em resposta à crise financeira internacional, o Comitê da Basileia divulgou um novo documento, conhecido como 
Basileia III, que dá sequência aos acordos I e II, e fornece uma estrutura regulamentar ao Sistema Financeiro para minimizar sua fragilidade nos pontos ainda não indicados nos documentos anteriores.

Conforme o BCBS (2011), cinco pontos principais foram pautas dessa atualização. Primeiro, melhoria na qualidade do capital de referência, com foco maior no capital que absorverá os impactos em caso de perdas, para que não prejudique a continuidade operacional. Segundo a determinação de novas exigências referente ao nível de capital para assegurar que em momentos de instabilidade haja maior aporte para suportar as perdas. Terceiro, a revisão na estrutura de capital ponderado pelo risco, englobando principalmente crédito e mercado.

O quarto ponto foi a adição de elementos prudenciais ao arcabouço regulatório, por meio de aspectos adicionados no capital principal: reservas de capital que são instituídas e desenvolvidas em épocas prósperas e podem ser utilizadas em momentos de declínio na economia para absorver perda e o estabelecimento de regras que mitiguem os riscos sistêmicos decorrentes de interligações entre instituições. Por fim, para o processo de aporte financeiro governamental dos bancos, conhecido como alavancagem, se especificou um requisito mínimo para o cálculo de coeficiente.

\subsection{Sistema Financeiro Nacional: resoluções aplicadas}

As instituições financeiras bancárias que possuem sede no Brasil fazem parte do Sistema Financeiro Nacional (SFN) e são supervisionadas e regulamentadas pelo $\mathrm{BCB}$, Conselho Monetário Nacional (CMN) e pela Comissão de Valores Imobiliários (CVM). Nesse universo, o Sistema Nacional de Crédito Cooperativo (SNCC) tem ampliado sua importância principalmente após a ampliação à possibilidade dos clientes associativos, concedido pela Resolução CMN n 3.058/2002, para as chamadas cooperativas de crédito mútuo formadas por pequenos empresários, e por 
meio da Resolução CMN n 3.106/2003, para as cooperativas de livre admissão de associados (PORFIRIO; FERNANDES; DANTAS, 2019).

O CMN definiu diversas resoluções que estão alinhadas com o Acordo da Basileia II e III e definem critérios que padronizam o gerenciamento e elaboração dos relatórios financeiros referentes à gestão de risco pelas instituições, como por exemplo, a Resolução $n^{\circ}$ 4.557/2017 que regulamenta o gerenciamento contínuo da estrutura de capital e de riscos, além da declaração de apetite por riscos, a Risk Appetite Statement (RAS), que devem considerar os tipos de riscos e níveis que a instituição está disposta e tem capacidade de assumir, suas estratégias, condições de competitividade e ambiente regulatório em que atua.

Tais normativas não se aplicam da mesma forma para as cooperativas de crédito, que apesar de serem parte do Sistema Financeiro Nacional, não possuem obrigatoriedade na divulgação dos relatórios financeiros referente ao gerenciamento de risco, conforme descrito no Art. 4 da Resolução 4.557/2017. As cooperativas de crédito, base de estudo para o presente artigo, são denominadas como instituições financeiras sem fins lucrativos. Apesar de oferecerem produtos e serviços financeiros como os bancos, possuem um diferencial, os clientes são os cooperados, também considerados como os "donos" do negócio.

Segundo a lei 5.764/1971, cooperativas são sociedades de pessoas, que possuem natureza jurídica própria e civil, constituídas com objetivo de prestar serviços aos associados. São classificadas em três níveis: singular, quando constituída por no mínimo 20 pessoas físicas com objetivo geral no mesmo tipo de atividade econômica; centrais quando constituídas por no mínimo três cooperativas singulares e confederações quando constituídas por no mínimo três cooperativas centrais. 


\subsection{Gerenciamento do Risco de Crédito}

O crédito pode ser um instrumento de estratégia de negócios a ser utilizado pelas instituições financeiras na concessão de empréstimos e financiamentos ou mesmo nos serviços financeiros prestados (Silva, 2014). Em virtude de que o pagamento de tomadores pode não se realizar no fluxo temporal, surge então o risco de crédito (MACHINSKI; MOREIRA; SILVA, 2019).

As cooperativas de crédito são instituições alternativas ao sistema bancário tradicional, tendo como característica o fato de que elas assumem riscos no financiamento de negócios, em benefício da comunidade, além de fomentar a formação de poupança e do microcrédito (PORFIRIO; FERNANDES; DANTAS, 2019). Segundo Muller e Righi (2018) um aspecto de fundamental importância para a gestão financeira é a estimação correta do risco, que deve ser pautada em medidas precisas. Esse processo não serve apenas para evitar possíveis prejuízos, mas também por obrigatoriedade legal.

O risco significa perigo ou possibilidade de perigo e segundo Brigham e Houston (1999) é a chance de ocorrer um evento desfavorável. A percepção de risco está atrelada a um grau de incerteza, ou seja, ocorre-se risco quando existe um desconhecimento de resultados futuros de algum evento, ou seja, de algum acontecimento ou ocorrência (TRAPP, 2005).

Um dos procedimentos preliminares da instituição financeira é a avaliação da viabilidade de conceder o crédito, que consiste em comparar as características ou padrões de comportamento de um solicitante com as características de outros solicitantes de crédito, e assim verificar a aproximação das características de um indivíduo com grupos de bons pagadores ou de inadimplentes, e assim estimar uma probabilidade de que ele não pague seu financiamento (BLUHM; OVERBECK; WAGNER, 2003; MACHINSKI; MOREIRA; SILVA, 2019). 
García, Giménez e Guijarro (2013) associam diversos tipos de riscos às operações de crédito, como o operacional, de mercado e o próprio denominado risco de crédito. O risco operacional refere-se ao risco de perda resultante de uma falha ou de um inadequado processo interno de controle, podendo ser gerado pelo homem, pelo sistema ou por eventos externos (AMARAL; BRAGA; FREITAS; NEVES, 2009).

O risco de mercado provém de mudanças não previstas nos preços ou nas taxas que influenciam o volume de operações e o valor da carteira, enquanto o risco de crédito é associado às possíveis mudanças na qualidade do tomador ou dos créditos (MACHINSKI; MOREIRA; SILVA, 2019). Para Trapp (2005), a sobrevivência de uma empresa baseia-se na gestão de seus riscos e para Chang, Jiménez-Martín, Maasoumi, McAleer, \& Pérez-Amaral (2019) o gerenciamento de risco empresarial quando feito de forma ineficaz tende a sinalizar mecanismos de controle inexatos que podem gerar prejuízo a longo prazo.

Willumsen, Oehmen, Stingl e Geraldi (2019) afirmam que o gerenciamento de riscos deve ser amplamente adotado, pois agrega valor à entidade, à medida que pode evitar perdas. Tais afirmações reforçam a necessidade da mensuração, reconhecimento e divulgação adequado dos riscos pelas instituições detentoras.

Apesar de um risco ser evento incerto, com base nas normas vigentes, pode ser identificado e mensurado. Portanto, o adequado controle gerencial de riscos é de extrema importância para que a administração identifique potenciais ameaças que norteiam sua organização e em qual grau as mesmas se encontram. No âmbito das instituições financeiras são previstos, pelo BCBS, critérios para a mensuração dos riscos de liquidez, de crédito, de mercado e operacional, que foram posteriormente regulamentados pelo $\mathrm{CMN}$.

Para o presente estudo foi escolhido como ponto principal a análise do gerenciamento do risco de crédito, pois de acordo com Buehler, Freeman e Hulme 
(2008) 60\% da ameaça para os bancos refere-se diretamente ao risco de crédito, enquanto Gasmi, Ghédira, Smiti e Soui (2019) citam que a avalição correta desse risco é de vital importância para a segurança da instituição. Além disso, Djeundje e Crook (2019) afirmam que modelos que envolvem pontuação de crédito são amplamente utilizados no objetivo de minimizar insolvência por parte de devedores.

Segundo a Resolução 2.682/1999, alguns itens básicos devem ser seguidos para a mensuração do risco de crédito. As operações de crédito são classificadas em níveis de risco em ordem crescente, de "AA" a " $\mathrm{H}$ ", onde "AA" indica o menor risco e " $\mathrm{H}$ " indica o maior risco de perda. Nos termos da Resolução 2.682/1999, os elementos mínimos para a classificação da operação de risco são, em relação ao devedor e seus garantidores, situação econômico-financeira, grau de endividamento, capacidade de geração de resultados, fluxo de caixa, administração e qualidade de controles, pontualidade e atrasos nos pagamentos, contingências, setor de atividade econômica e limite de crédito. Em relação à operação da instituição financeira bancária, natureza e finalidade da transação, características das garantias e valor.

Segundo Goldstein e Yang (2019) após uma crise financeira frequentemente se chega à conclusão de que é necessário aumentar a divulgação de informações mais precisas, tal ato é conhecido como disclosure, que é a divulgação de dados financeiros e contábeis e possui como objetivo central a transparência organizacional. A correta evidenciação permite ao usuário, seja sobre o gerenciamento corporativo ou de investimento, que a tomada de decisões seja realizada com eficiência, logo, minimizase as chances de possíveis perdas.

Aquino e Santana (1992) indicam a necessidade da utilização de precaução ao se definir a maneira com que uma informação é evidenciada, pois a forma eleita determinará diretamente qual será o grau de esclarecimento possível a ser adquirido pelo usuário de destino. Em adendo, Goldstein e Yang (2017) definem que a estrutura informacional propagada afetará diretamente a qualidade do mercado financeiro, a 
eficiência de decisões reais e o bem-estar geral, pois os tomadores de decisão utilizarão tais dados como orientação para tomada de decisões.

Diversos estudos internacionais foram realizados a respeito da implantação do gerenciamento de risco proveniente do Acordo da Basileia, como por exemplo, o de Hakenes e Schnabel (2010) nos Estados Unidos sobre a adoção da gestão de risco com base em uma abordagem padronizada, sob a ótica do modelo de concorrência imperfeita e risco moral.

Os resultados demonstraram que os custos para tal feito são altos e, portanto, os maiores bancos utilizam o IRB, que é instituído pelo regulador internacional, e os menores permanecem com a abordagem convencional, pois possuem dificuldade na absorção dos gastos necessários para a implantação. Weill e Zins (2017) levantaram dados dos 24 países que possuem presença bancária islâmica entre 2007 e 2013, totalizando 558 bancos, realizaram um comparativo entre seguir ou não a regulamentação prudencial, e como conclusão obtiveram que os que começaram a seguir o processo prudencial diminuíram bruscamente o risco.

Hamadi, Heinen, Linder e Porumb (2016) coletaram uma amostra de relatórios do ano de 2008 provenientes de instituições bancárias de 24 países europeus, para verificar o efeito que o Acordo de Capital da "Basileia II" teve sobre a avalição de mercado para provisão de perdas com empréstimos. Eles concluíram que a mudança nas regulamentações prudenciais destinadas a promover a estabilidade financeira teve um impacto positivo significativo nas práticas de provisionamento pelos bancos.

Sobre as instituições bancárias do SFN dois estudos possuem destaque. Primeiramente, Trapp e Corrar (2005) que realizou uma avaliação qualitativa referente ao risco operacional em uma instituição financeira brasileira, por meio de análise dos instrumentos utilizados pela entidade e o nível de desenvolvimento em que se encontrava. O segundo também realizado em fase de implementação da 
normativa dos pilares da Basileia II, de Dantas et al. (2010) que por meio de uma análise de regressão em dados em painel com uma amostra dos 50 maiores bancos do SFN permitiu analisar o grau de evidenciação do gerenciamento de risco de crédito e verificaram que houve um aumento paulatino no mesmo, assim como, encontraram estatisticamente que as variáveis tamanho do ativo (TAM), instituições de controle privado (TC), rentabilidade (RENT), índice da Basileia (II), Bovespa (BOV) influenciam diretamente no DRC.

Referente à amostra de cooperativas de crédito, alguns estudos foram realizados referentes à gestão de risco. Como por exemplo, Hein, Magro e Mondini (2015) que realizaram uma pesquisa quantitativa a respeito do perfil de inadimplência na tomada de crédito na região oeste de Santa Catarina. Amaral et al. (2009) realizaram um estudo de caso sobre os mecanismos utilizados para o gerenciamento de risco. Lavarda, Padilha e Santana (2015) por meio de uma pesquisa descritiva verificaram as incertezas que podem afetar o sistema de controle gerencial.

\subsection{Hipóteses de Pesquisa}

Como propósito central, esta pesquisa busca verificar se as cooperativas centrais de crédito possuem o mesmo grau de evidenciação das instituições bancárias típicas do SFN e se as variáveis representativas de ativo, índice da basileia, imobilizado e rentabilidade impactam no grau de evidenciação, por meio de análise estatística inferencial.

Para Ponte e Oliveira (2004), a disponibilização de dados, quando livre da obrigação legislativa, conota ética e responsabilidade corporativa por parte das organizações, além disso, a transparência de dados afeta positivamente o desenvolvimento bancário (Webber, 2019). Guimarães, Pereira, Weffort, \& Machado (2005) afirmam que a evidenciação da informação relativa à empresa é essencial para o posicionamento da mesma no mercado de um modo geral. 
A legislação determina quais são as características fundamentais a serem analisadas para determinação do risco de crédito e qual deve ser o grau de divulgação a ser evidenciado pelas instituições financeiras. Conforme resolução 4557/2017, as cooperativas de crédito não possuem obrigatoriedade na publicação detalhada como os bancos que compõem o SFN. Diante disso, a primeira hipótese de pesquisa não estatística propõe queH1 As Cooperativas de Crédito possuem um menor grau de evidenciação dos riscos de crédito, haja vista a falta de obrigatoriedade para o segmento.

Salotti e Yamamoto (2008) confirmaram em seu estudo a relação entre as variáveis custo e divulgação, assim como, Hakenes e Schnabel (2010) afirmam que a implantação do gerenciamento de risco possui altos custos. No âmbito da divulgação voluntária, Murcia e Santos (2009) destacam ser os riscos um dos principais pontos de evidenciação das maiores empresas. Para as instituições financeiras tradicionais, Dantas et al. (2010) identificou que o porte seria uma variável explicativa do grau de evidenciação.

Portanto, pode influenciar diretamente no grau de evidenciação do risco, quando não obrigatório, por cooperativas de menor porte, já que possuem um suporte menor para absorção destes gastos. A seguinte hipótese foi elaborada para verificar se tais expectativas correspondem à realidadeH2. As cooperativas de crédito de maior porte divulgam mais sobre gerenciamento de risco de crédito que as de menor porte.

A relação entre desempenho e evidenciação é constantemente testada na literatura referente a disclosure. Vários estudos, como por exemplo o de Healy, Palepu e Ealy (2001), Eng e Mak (2003) e também de Aren, Kayagil e Aydemir (2014), confirmam que a relação entre estas variáveis é diretamente proporcional. 
Dantas et al. (2010) identificou que a rentabilidade é capaz de explicar o grau de evidenciação das instituições financeiras tradicionais. Com base nestas informações, a hipótese a seguir foi desenvolvida H3 As cooperativas de crédito que apresentam melhores indicadores de rentabilidade e de gestão divulgam mais informações sobre gerenciamento de risco de crédito.

\section{MÉTODO DE PESQUISA}

O presente artigo adota uma metodologia quantitativa quanto ao problema e explicativo-descritivo quanto aos objetivos. Para operacionalização, foram empregados os procedimentos estabelecidos por Dantas et al. (2010) pela referência ao desenvolvimento da métrica para instituições financeiras bancárias, e pela possibilidade de comparação dos resultados.

Para análise estatística, foi adotada a regressão em painel, por conta do corte transversal das cooperativas e da variação temporal (FURTADO FILHO; FLACH; SALLABERRY, 2019). Inicialmente foi preciso transformar os requisitos de divulgação de riscos em variável quantitativa, para os quais foi estabelecida a média da evidenciação de cada indicador regulamentado, descritos na Tabela 1.

Tabela 1 - Instrumento de Coleta - Divulgação de Risco de Crédito

\begin{tabular}{|c|c|c|c|}
\hline Eixo & Tipo & Cód. & Item de divulgação \\
\hline \multirow[t]{2}{*}{$\begin{array}{c}\text { Risco de } \\
\text { crédito - } \\
\text { divulgações } \\
\text { gerais para } \\
\text { todos os } \\
\text { bancos }\end{array}$} & $\begin{array}{l}\text { Divulgações } \\
\text { Qualitativas }\end{array}$ & A & $\begin{array}{l}\text { Exigência de divulgação qualitativa geral (\$824) a } \\
\text { respeito de risco de crédito, incluindo: definições de } \\
\text { itens vencidos e com valores reduzidos (para fins } \\
\text { contábeis); Descrição dos métodos usados para as } \\
\text { provisões gerais e específicas e dos métodos } \\
\text { estatísticos; discussão da política de administração de } \\
\text { riscos de crédito do banco. }\end{array}$ \\
\hline & Divulgações & B & Total bruto das exposições a risco de crédito mais a \\
\hline
\end{tabular}




\begin{tabular}{|c|c|c|c|}
\hline & Quantitativas & & $\begin{array}{l}\text { média da exposição bruta durante o período, dividido } \\
\text { pelos principais tipos de exposição de crédito. }\end{array}$ \\
\hline & & C & $\begin{array}{l}\text { Distribuição geográfica de exposições, desdobradas em } \\
\text { áreas significativas pelos principais tipos de exposição } \\
\text { de crédito. }\end{array}$ \\
\hline & & $\mathrm{D}$ & $\begin{array}{l}\text { Distribuições de exposições do tipo do setor e das } \\
\text { partes contratantes, desdobradas pelos principais tipos } \\
\text { de exposição de crédito. }\end{array}$ \\
\hline & & $\mathrm{E}$ & $\begin{array}{l}\text { Desdobramento de vencimentos contratuais residuais } \\
\text { de toda a carteira, desdobrados pelos principais tipos de } \\
\text { exposição de crédito. }\end{array}$ \\
\hline & & $\mathrm{F}$ & $\begin{array}{l}\text { Pelo tipo principal do setor ou das partes contratantes: } \\
\text { valor de empréstimos prejudicados e, se disponíveis, } \\
\text { empréstimos vencidos, fornecidos separadamente; } \\
\text { provisões específicas e gerais; e encargos para } \\
\text { provisões específicas e baixas durante o período }\end{array}$ \\
\hline & & G & $\begin{array}{l}\text { Valor dos empréstimos deteriorados e, se disponível, } \\
\text { empréstimos vencidos fornecidos separadamente, } \\
\text { desdobrados pelas áreas geográficas significativas } \\
\text { incluindo, se for praticável, os valores de provisões } \\
\text { específicas e gerais relacionadas a cada área geográfica. }\end{array}$ \\
\hline & & $\mathrm{H}$ & $\begin{array}{l}\text { Reconciliação de mudanças nas provisões para redução } \\
\text { do valor de empréstimos. }\end{array}$ \\
\hline $\begin{array}{l}\text { Diminuição } \\
\text { de risco de } \\
\text { crédito - } \\
\text { divulgações } \\
\text { para os } \\
\text { métodos } \\
\text { padronizados }\end{array}$ & $\begin{array}{l}\text { Divulgações } \\
\text { Qualitativas }\end{array}$ & I & $\begin{array}{l}\text { Exigência de divulgação qualitativa geral a respeito da } \\
\text { diminuição de risco de crédito incluindo: as políticas e } \\
\text { processos para liquidação por compensação registrada } \\
\text { e não registrada no balanço patrimonial, e uma } \\
\text { indicação da extensão na qual o banco faz o uso dessa } \\
\text { liquidação; as políticas e processos para administração e } \\
\text { avaliação de caução; uma descrição dos principais tipos } \\
\text { de caução obtidas pelo banco; os principais tipos de } \\
\text { avalistas/partes contratantes de derivativos de crédito e } \\
\text { sua capacidade financeira de obter crédito; e as } \\
\text { informações sobre concentrações de risco (de mercado } \\
\text { ou crédito) dentro da diminuição feita. }\end{array}$ \\
\hline
\end{tabular}




\begin{tabular}{l|l|l|l}
\hline \multirow{2}{*}{ Divulgações } & $\mathrm{J}$ & $\begin{array}{l}\text { Para cada carteira de risco de crédito divulgada, a } \\
\text { exposição total (após, quando for aplicável, a liquidação } \\
\text { Quantitativas }\end{array}$ & $\begin{array}{l}\text { por compensação registrada ou não registrada no } \\
\text { balanço patrimonial) que é abrangida caução financeira } \\
\text { qualificada. }\end{array}$ \\
\cline { 3 - 4 } & $\mathrm{K}$ & $\begin{array}{l}\text { Para cada carteira de risco de crédito divulgada, a } \\
\text { exposição total (após, quando for aplicável, a liquidação } \\
\text { por compensação registrada ou não registrada no } \\
\text { balanço patrimonial) que é abrangida por } \\
\text { garantias/derivativos de crédito. }\end{array}$ \\
\hline
\end{tabular}

Fonte: Dantas et al. (2010).

Esta pesquisa realiza uma análise direcionada ao risco de crédito das cooperativas de crédito, enquadradas na classificação como centrais, que se encontram ativas no SFN (2015 a 2018). A amostra em análise abrange 21 centrais de cooperativas de crédito com dados disponíveis dos Relatórios Financeiros Trimestrais (IFT) das instituições, no período de 2015 a 2018, disponíveis na plataforma IfData, do BCB.

A escolha pelas centrais de cooperativas ocorreu porque as cooperativas singulares não possuem plataforma de divulgação dos dados, sendo que se utilizam de uma estrutura central, que consolida muitas dessas informações, além de que as cooperativas individualmente não possuem tal obrigação de divulgação. No sistema cooperativo de crédito brasileiro as entidades se organizam sob uma estrutura piramidal, em que as cooperativas singulares ocupam a base, e as cooperativas centrais ocupam o nível acima (PORFIRIO; FERNANDES; DANTAS, 2019), compostas de pelo menos três cooperativas singulares.

O modelo explicativo do grau de divulgação será empregado a partir da modelagem de variáveis tendo por base a métrica aplicada por Dantas et al. (2010), após ajustes ao segmento em análise e a janela temporal em estudo: 
$D R C_{i t}=\propto+\beta_{1} L n T A M_{i t}+\beta_{2} I B_{i t}+\beta_{3} I I_{i t}+\beta_{4} R E N T_{i t}+\varepsilon i_{i t}(1)$

Sendo:

DRC - Grau de Divulgação do risco de crédito da instituição i, no período t, apurado na pesquisa a partir da análise de conteúdo das IFT de cada instituição entre 2015 e 2018;

$\mathrm{TAM}_{\mathrm{i}, \mathrm{t}}$ - Medida que representa o tamanho da instituição i no período $t$, apurada pela relação entre os ativos totais e a soma desses ativos em todo o segmento.

$\mathrm{IB}_{\mathrm{i}, \mathrm{t}}$ - Traduz o índice de Basiléia da instituição i, no período $\mathrm{t}$, apurado e divulgado pelo $B C$.

$\|_{i, t}$ - Índice de imobilização da instituição i, no período $t$, apurado e divulgado pelo BC. $R E N T_{i, t}$ - Traduz a rentabilidade da instituição i, no período t, definida como a relação entre o lucro líquido e o patrimônio líquido ajustado (deduzido do lucro ou prejuízo líquido do período) em cada período examinado.

A identificação e desenvolvimento da variável DRC é apurada mediante a análise das plataformas das cooperativas de crédito. Para a apuração das notas individualizadas, foram analisados os relatórios divulgados pelas cooperativas sendo atribuído 0 (zero) quando não atende aos requisitos de divulgação e 1 (um) quando atende completamente à exigência de divulgação. A partir desta atribuição em relação a cada item de divulgação, descritos na Tabela 1, foi apurado o grau de divulgação do risco de crédito da instituição $i$, para cada período $t$, que é representado como variável DRC.

As demais variáveis tamanho (TAM) antes da transformar em logaritmo, índice de Basiléia (IB), índice de imobilização (II), e rentabilidade (RENT) foram coletadas diretamente da base de dados IfData do Banco Central do Brasil (BCB). O BCB recebe os dados das variáveis diretamente das instituições financeiras e as mantém em banco de dados. 
A variável de tamanho refere-se ao total do ativo das organizações analisadas e foi coletada a partir do banco de dados IfData, que é mantido pelo $B C B$, que apresentou estagnação nos dois primeiros anos (2015-2016), seguido de crescimento em 2017 e 2018. Para a inferência estatística os valores foram transformados em logaritmo, para que os dados não tivessem uma discrepância que pudesse afetar as demais variáveis.

O Índice da Basileia, denominado na metodologia como IB, é um valor obtido sobre o patrimônio de referência e os ativos que são ponderados pelo risco. Percebese uma diminuição relevante do índice de Basiléia para 2017 com recuperação parcial em 2018.

O Índice de Imobilização, definido anteriormente pela sigla II, é um valor que indica o nível de dependência de fundos de terceiros, pois identifica o quanto do patrimônio líquido da instituição está aplicado no ativo permanente da instituição. Observa-se redução relevante em 2016, com crescimento superior em 2017 e posterior retração parcial, que de certa forma é influenciado pelas condições econômicas e incertezas políticas dos últimos anos.

A Rentabilidade, ou RENT, é calculada a partir da divisão entre o lucro líquido e o patrimônio ajustado, os valores foram coletados no banco de dados IfData. É importante destacar que alguns valores encontrados se enquadraram como outliers e por este motivo foram tratados para que não prejudicassem na análise estatística. Os resultados evidenciam redução continuada na rentabilidade dos últimos anos, que pode ser uma sinalização dos resultados da crise econômica (SALLABERRY; MEDEIROS, 2015).

Para a análise estatística, a equação agregada de outras variáveis à época foi estatisticamente relevante para explicar o grau de evidenciação do risco de crédito 
(DANTAS et al., 2010), sendo que nem todas as variáveis foram significantes para a amostra testada. Para o modelo descrito será aplicado como metodologia estatística a análise por dados em painel curto, por considerar uma amostra ao longo de um período, cujo quantitativo de cooperativas maior do que o quantitativo de períodos (2015 a 2018).

Para eleger o método mais adequado, entre POLS, efeitos aleatórios ou efeitos fixos, foram realizados os testes, Breusch-Pagan e F de Chow, indicados por Fávero, Belfiore, Suzart e Takamatsu (2014). O primeiro teste faz um comparativo entre efeitos aleatórios e POLS e o segundo entre efeitos fixos e POLS.

\section{RESULTADOS}

\subsection{Requisitos de divulgação}

Para que o Disclosure do Risco de Crédito (DRC) fosse evidenciado foi necessário realizar os procedimentos de transformação dos itens considerados como requisitos essenciais em um valor numérico conforme declarado na metodologia. A técnica escolhida para tal situação foi a realização da média aritmética a partir da observação dos dados divulgados pelas cooperativas de crédito, do item presente recebendo 1, e na ausência recebendo pontuação 0, quantificados na tabela 2.

Para a obtenção de uma visão geral do grau de disclosure das cooperativas de crédito, todas as observações encontradas foram somadas e divididas pelo total de instituições selecionadas para a coleta. Como resultado, foram obtidas as seguintes médias para cada requisito indicado na tabela 1, na qual é possível concluir que os itens A e B são amplamente divulgados, obtendo 100\% e que para a média total o que obteve menor divulgação no período foi a evidência do item K - exposição das garantias e derivativos de crédito. 
Essa evolução pode ser percebida de forma detalhada na tabela 2. A média de cada item por ano coletado evidencia que para a maioria dos atributos houve um aumento na evidenciação por parte das instituições analisadas, perceptível em análise gráfica (figura 1).

Tabela 2- Média dos Indicadores (2015-2018)

\begin{tabular}{ccccccccccccc}
\hline Ano & A & B & C & D & E & F & G & H & I & J & K & Média \\
\hline 2015 & 1,00 & 1,00 & 0,10 & 0,95 & 0,95 & 0,19 & 0,10 & 0,10 & 0,14 & 0,10 & 0,00 & $\mathbf{0 , 4 2}$ \\
2016 & 1,00 & 1,00 & 0,05 & 0,95 & 0,90 & 0,62 & 0,48 & 0,24 & 0,57 & 0,38 & 0,14 & $\mathbf{0 , 5 8}$ \\
2017 & 1,00 & 1,00 & 0,29 & 0,95 & 0,95 & 0,81 & 0,57 & 0,48 & 0,67 & 0,52 & 0,29 & $\mathbf{0 , 6 9}$ \\
2018 & 1,00 & 1,00 & 0,57 & 0,95 & 0,95 & 0,81 & 0,71 & 0,48 & 0,57 & 0,62 & 0,29 & $\mathbf{0 , 7 3}$ \\
\hline
\end{tabular}

Fonte: Elaborada pelos Autores

Figura 1 - Gráfico da Evolução dos Indicadores de Evidenciação do Risco

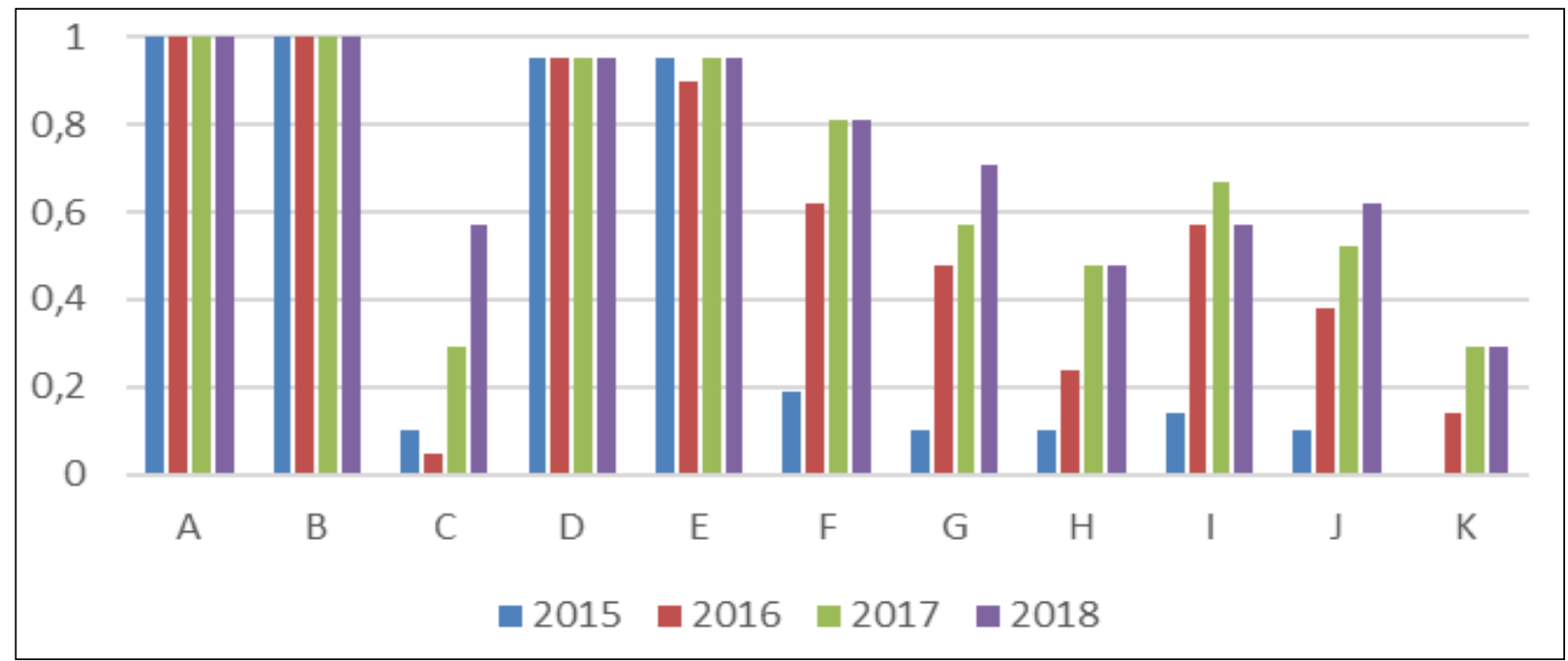

Fonte: Elaborado pelos Autores 
4.2 Variáveis observadas

A partir da aplicação dos procedimentos descritos no escopo metodológico, as variáveis DRC, TAM, IB, II, RENT foram analisadas. A DRC foi utilizada como variável dependente no modelo estatístico, e as demais foram testadas, a partir das hipóteses descritas no referencial, para verificar se há significância estatística das variáveis que determinam o grau de evidenciação do gerenciamento de risco de crédito. A partir da amostra, foram observados os dados descritivos de cada variável, evidenciadas na Tabela 3.

Tabela 3 - Estatística Descritiva das Variáveis (2015 - 2018)

\begin{tabular}{c|c|c|c|c|c|c|c|c|c|c}
\hline \multirow{2}{*}{ Ano } & \multicolumn{2}{|c|}{ DRC } & \multicolumn{2}{c|}{ LnTAM } & \multicolumn{2}{c|}{ IB } & \multicolumn{2}{c|}{ II } & \multicolumn{2}{c}{ RENT } \\
\cline { 2 - 10 } & Med & DP & Med & DP & Med & DP & Med & DP & Med & DP \\
\hline \multirow{2}{*}{2015} & 0,418 & 0,147 & 6,96 & 1,30 & 24,25 & 14,43 & 10,74 & 13,09 & 2 & 0,052 \\
\hline \multirow{2}{*}{2016} & 0,578 & 0,182 & 6,94 & 1,36 & 24,91 & 14,57 & 8,45 & 10,56 & 2 & 0,060 \\
\hline \multirow{2}{*}{2017} & 0,685 & 0,175 & 7,04 & 1,35 & 21,92 & 10,19 & 11,79 & 19,22 & 5 & 0,069 \\
\hline & & & & & & & & & 0,033 & \\
2018 & 0,733 & 0,171 & 7,14 & 1,26 & 23,14 & 12,79 & 11,00 & 14,00 & 9 & 0,056 \\
\hline
\end{tabular}

Fonte: Elaborada pelos Autores

O grau de evidenciação, denominado na metodologia como DRC, foi calculado a partir da média aritmética dos requisitos de divulgação do risco de crédito, definidos pelo Acordo da Basileia II e descritos na tabela 1. Na tabela 3, percebe-se que a média teve um aumento gradual, o que demonstra que as cooperativas de crédito aumentaram gradativamente a evidenciação da gestão de risco de crédito no 
período entre 2015 a 2018, ainda assim, abaixo do limite superior, que seria a evidenciação total esperada, confirmando a hipótese 1 da pesquisa.

\subsection{Verificação estatística: Dados em Painel}

A análise estatística inferencial empregou o método de regressão de dados em painel por considerar as variações entre indivíduos e períodos, adequado às características dos dados coletados. Para a definição do modelo dos efeitos do painel a ser aplicado foram realizados os testes Breusch-Pagan ( $\chi 2=0,07$, sig. 0,3981) e teste $F$ de Chow ( $F=1,32$, sig $F$ 0.2037), cujos resultados não permitiram a rejeição da hipótese de que há igualdade de interceptos e inclinações para todas as entidades, e, portanto, a aplicação de painel POLS é a adequada (FAVERO et al., 2014).

Como os parâmetros desse modelo são estimados por meio de POLS, mas o método de regressão requer o controle da correlação within do erro $\mu_{\text {it }}$ para um dado indivíduo, optou-se pelo modelo POLS com Erros-Padrão Robustos Clusterizados (FAVERO, 2013). O modelo apresentou significância em duas das quatro variáveis do modelo, demonstrando uma capacidade explicativa de $29 \%\left(R^{2}=0.2928\right)$.

Tabela 4 - Resultados da Regressão POLS

\begin{tabular}{l|l|l|l|l}
\hline DRC & Coef. & Std. Err & $\mathbf{t}$ & $\mathbf{P}>|\mathbf{t}|$ \\
\hline LnTAM & .0496527 & .0165161 & 3.01 & 0.007 \\
\hline IB & .000644 & .0018201 & 0.35 & 0.727 \\
\hline II & -.0048882 & .0008952 & -5.46 & 0.000 \\
\hline RENT & -.2825184 & .2290763 & -1.23 & 0.232 \\
\hline
\end{tabular}

Fonte: Elaborada pelos Autores 
Segundo os outputs constantes da tabela 4, foi encontrada significância para as variáveis tamanho (LnTAM) e índice de imobilização (II), corroborando Dantas et al. (2010) em significância e sentido, tanto para a aplicação dos modelos fixos ou aleatórios na referida pesquisa. Estes resultados demonstram que o comportamento das instituições financeiras típicas ocorre de forma semelhante nas cooperativas de crédito.

A hipótese de que o tamanho da entidade (variável LnTAM) tem influência positiva na divulgação dos riscos (variável DRC) é confirmada, corroborando Dantas et al. (2010) em significância e sentido positivo, entretanto o coeficiente é três vezes superior nas cooperativas de crédito do que nas instituições bancárias típicas, sinalizando um maior impacto do tamanho na divulgação dos riscos nas cooperativas.

A hipótese também confirma os estudos de Salotti e Yamamoto (2008) e Hakenes e Schnabel (2010) que afirmam que a implementação do gerenciamento de risco trás altos custos e que organizações menores, ou seja, com ativo de menor tamanho, possuem mais dificuldade para suportar os gastos operacionais. Entidades menores, ativo de menor tamanho, tendem a ter menor lucro, muitas vezes incompatível com o custo fixo de instalação de uma política de divulgação de riscos mais robusta. Assim, a hipótese 2 é confirmada.

A hipótese referente ao Índice de Imobilização (variável II) também corrobora o estudo de Dantas et al. (2010) para as instituições financeiras típicas, em significância e sentido, haja vista que ambos identificaram um sinal negativo para a variável. Isto posto, quanto maior a imobilização do capital das cooperativas de crédito, menor a divulgação dos riscos.

De certa forma, a função da variável tem uma interpretação semelhante ao tamanho, uma vez que quanto mais ativos aplicados em ativos do imobilizado, menor a proporção do capital circulante nas atividades negociais da cooperativa de crédito, 
consequentemente menor lucro e capacidade de suportar a instalação e organização da divulgação dos riscos. Assim, reforça a confirmação da hipótese 2.

A hipótese 3, de que empresas com maior evidenciação são premiadas com maior rentabilidade não foi confirmada, haja visto que tanto a variável RENT, quanto o IB - Índice de Basiléia - não foram estatisticamente significativas. Estes resultados corroboram parcialmente os resultados de Dantas et al. (2010) para as instituições bancárias típicas.

O esperado seria que as instituições com os melhores indicadores de rentabilidade e de gestão divulguem mais informações sobre o risco de crédito, o que não foi confirmado. A análise detalhada dos dados pode permitir insights sobre potenciais argumentos dessa ausência de significância na relação esperada, por isso demonstrada na figura 2.

Figura 2 - Relação entre Divulgação de Riscos e Rentabilidade (2015 - 2018)

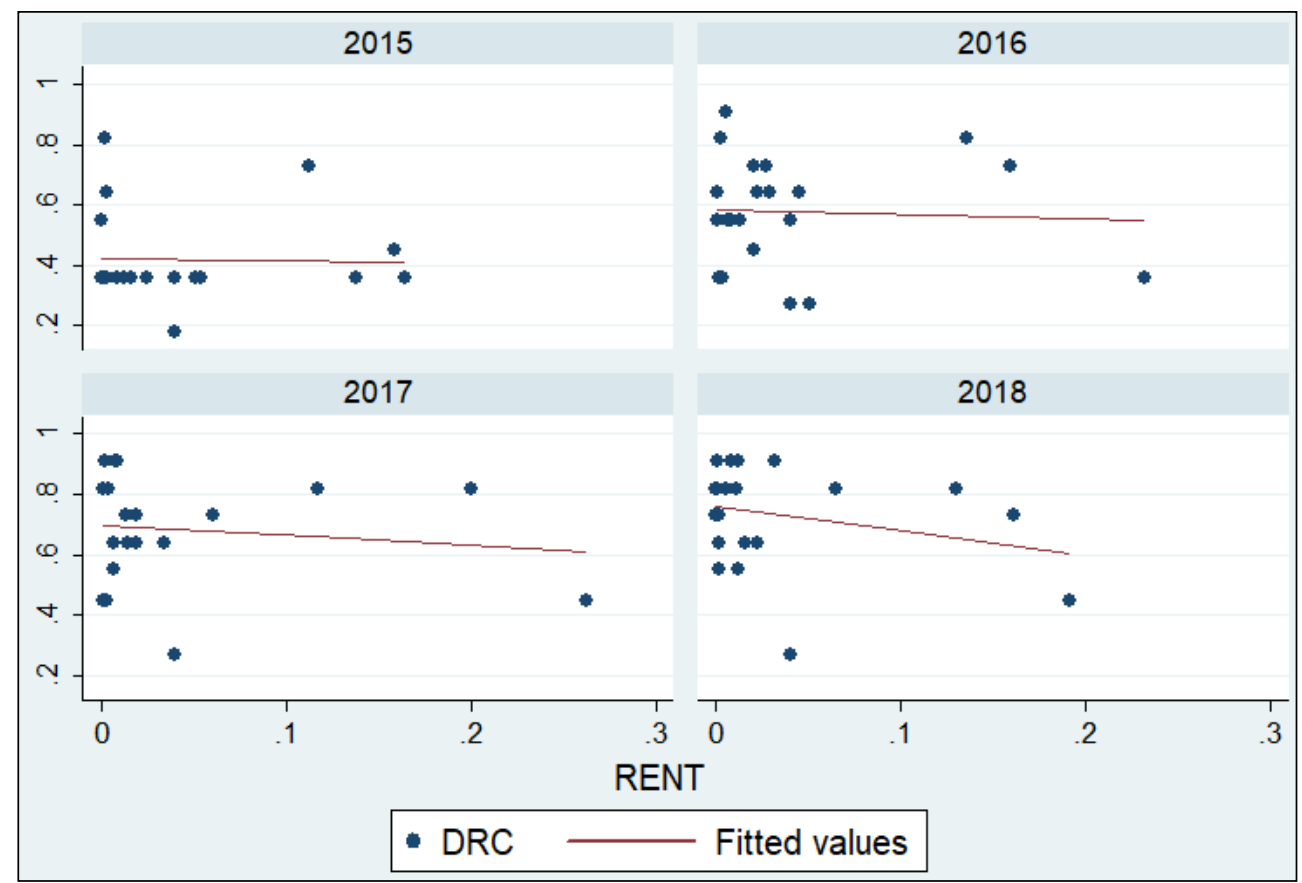

Fonte: Software STATA - dados da pesquisa 
A análise detalhada dos dados evidência que apesar da variação na divulgação dos riscos, a rentabilidade tem se agrupado em baixos índices, possivelmente pela influência da crise econômica nos últimos anos, o que dificulta a identificação de variação proporcional nas variáveis capazes de demonstrar significância. Além disso, o fato de serem apenas 21 centrais de cooperativa de crédito com dados disponíveis, mitiga o poder inferencial estatístico.

\section{CONCLUSÃO}

Este artigo teve como objetivo principal a análise do grau de aderência à divulgação dos riscos de crédito nas cooperativas financeiras e seus determinantes, tendo como referência principal o estudo realizado por Dantas et al. (2010) para as instituições financeiras típicas. A principal motivação para o estudo foi que o adequado gerenciamento de risco pode auxiliar na tomada de decisões e minimização de perdas, além disso, a risco de crédito possui relevância para uma instituição, pois eventual insolvência impacta diretamente no negócio financeiro.

As cooperativas de crédito classificadas como centrais no período entre 2015 a 2018, no quantitativo de 21 centrais cooperativas de crédito tiveram seus dados coletados e analisados. Os resultados encontrados referentes aos itens descritos evidenciam que as cooperativas apresentam um grau de divulgação dos riscos de crédito inferior ao comparativo esperado das instituições financeiras tradicionais, embora demonstrando que houve um aumento gradual na maioria dos requisitos verificados, o que demonstrou um aumento no período na evidenciação por parte das instituições que foram analisadas.

Sobre as variáveis que foram consideradas, a DRC como consequência do aumento do valor de alguns indicadores, também foi impactada positivamente em sua média. Os resultados evidenciaram que da mesma forma que as instituições financeiras bancárias, as cooperativas de crédito relacionam a evidenciação ao seu 
tamanho, decorrente dos altos custos de implementação de controles. Foram corroboradas as variáveis: Tamanho e Índice de Imobilização.

Esses resultados contribuem ao indicar que no mercado financeiro o tamanho da instituição é relevante para diversos fatores, inclusive da para divulgação dos riscos, pois as obrigações as quais instituições financeiras são submetidas exigem gastos relevantes e em pequenas instituições podem expor dificuldades operacionais. De outra forma, essa relação entre tamanho da organização e índice de imobilização com o grau de evidenciação pode indicar que o problema não seria o tamanho da organização para arcar com os gastos, mas sim a complexidade da evidenciação que gera custos elevados, sem representar uma maior exposição da instituição cooperativa. Essa é uma implicação teórica passível de maior investigação.

Todavia a hipótese de que empresas com maior evidenciação são premiadas com maior rentabilidade não foi confirmada, haja vista que as variáveis rentabilidade e índice de Basiléia não foram significantes estatisticamente. Essa relação é prejudicada pelo fato da alta concentração da amostra com baixa rentabilidade, mitigada pela baixa quantidade de cooperativas da amostra. $O$ esperado seria que as instituições com os melhores indicadores de rentabilidade e de gestão divulguem mais informações sobre o risco de crédito (DANTAS et al., 2010).

A evolução dos princípios e objetivos dos acordos de Basiléia podem ter gerado ações e comportamentos que ampliaram a evidenciação no decorrer dos anos, mas a exemplo das instituições financeiras não cooperativas, a variável do índice de Basiléia não foi estatisticamente significativa (Dantas et al., 2010). Como diferencial, as cooperativas de crédito tem opção de adoção de um regime simplificado de apuração do índice da Basiléia pela desconsideração de alguns riscos no denominador, gerando um indicador superior o que não se relacionaria com o nível de divulgação, em princípio; além disso, a aplicabilidade de diferentes opções de apuração gera maior variabilidade e portanto dificuldade da validação de um comportamento. Assim, a 
pesquisa contribui com a literatura sobre disclosure de riscos de crédito ao abordar uma amostra ainda não estudada dessa forma, com a indicação das variáveis que influenciam o nível de evidenciação (Tamanho e Imobilização) bem como os fatores que demonstraram não estar relacionados (Índice de Basiléia e Rentabilidade), bem como as implicações que as discussões sobre as relações foram abordadas. Como implicação prática, o estudo evidencia a maior fragilidade da divulgação das instituições cooperativas, mas que podem ser mitigadas pelo maior agrupamento (tamanho) de cooperativas singulares.

Como principal limitação do estudo, encontrou-se a dificuldade na coleta de dados nos relatórios das organizações, por muitas vezes, quando divulgados, os mesmos se encontram em diferentes tipos de relatórios e locais. Sugere-se para estudos futuros a realização de testes estatísticos para uma amostra maior, com busca de dados de divulgação em outras bases, para aumentar a possibilidade de se encontrar relações entre variáveis com significância e consequentemente verificar se as variáveis corroboram com as hipóteses.

\section{REFERÊNCIAS}

AMARAL, I. et al. Gerenciamento dos riscos operacionais: os métodos utilizados por uma cooperativa de crédito. Revista de Contabilidade e Organizações, v. 3, n. 7, p. 93-108, 2009.

AQUINO, W.; SANTANA, A.C. Evidenciação. Caderno de estudos, n. 5, p. 01-40, 1992.

AREN, S.; KAYAGIL, S.O.; AYDEMIR, S.D. The determinants and effects of corporate governance level: Evidence from Istanbul Stock Exchange. Procedia-Social and Behavioral Sciences, v. 150, p. 1061-1070, 2014. 
BCB. Banco Central do Brasil. Legislação. Acesso em: 19 ab. 2019. Disponível em: www.bcb.gov.br.

BCBS. Basel Committe on Banking Supervision's. Basel III: A global regulatory framework for more resilient banks and banking systems. 2011. Acesso em: 18 abr. 2019. Disponível em: www.bis.org/publ/bcbs189.html.

BLUHM, C.; OVERBECK, L.; WAGNER, C. Introduction to credit risk modeling. CrC Press, 2003.

BRIGHAM, E.F.; HOUSTON, J.F. Fundamentos da moderna administração financeira. Campus, 1999.

BUEHLER, K.; FREEMAN, A.; HULME, R. Owning the right risks. Harvard Business Review, v. 86, n. 9, p. 102-110, 2008.

CHANG, C. et al. Choosing expected shortfall over VaR in Basel III using stochastic dominance. International Review of Economics \& Finance, v. 60, p. 95-113, 2019. Doi. http://dx.doi.org/10.1016/j.iref.2018.12.016. CHAVES, S. S. O cooperativismo de crédito no Brasil: evolução e perspectivas.

Desafios do Sistema Financeiro Nacional: o que falta para colher os benefícios da estabilidade conquistada. Rio de Janeiro: Elsevier-Campus, p. 69-97, 2011.

CUNHA, M.M.B; et al. Os Acordos de Basileia I, II, III e o mercado bancário brasileiro: um estudo sobre os principais desafios da gestão de liquidez nesse novo cenário. Mestrado em Ciências Contábeis e Atuariais, Pontifícia Universidade Católica de São Paulo, 2014. 
DANTAS, J.A. et al. Determinantes do grau de evidenciação de risco de crédito pelos bancos brasileiros. Revista Contabilidade \& Finanças, v. 21, n. 52, p. 1-27, 2010. Doi. http://dx.doi.org/10.1590/S1519-70772010000100002.

DJEUNDJE, V.B.; CROOK, J. Dynamic survival models with varying coefficients for credit risks. European Journal of Operational Research, v. 275, n. 1, p. 319-333, 2019. Doi. https://doi.org/10.1016/j.ejor.2018.11.029.

ENG, L.L.; MAK, Y.T. Corporate governance and voluntary disclosure. Journal of accounting and public policy, v. 22, n. 4, p. 325-345, 2003. Doi. https://doi.org/10.1016/S0278-4254(03)00037-1.

FÁVERO, L.P.; BELFIORE, P. Métodos Quantitativos com Stata: Procedimentos, Rotinas e Análise de Resultados. Elsevier Brasil, 2014.

FÁVERO, L.P.L. Dados em painel em contabilidade e finanças: teoria e aplicação. BBRBrazilian Business Review, v. 10, n. 1, p. 131-156, 2013.

FRANCISCO, J.R.S.; AMARAL, H.F.; BERTUCCI, L.A. Risco de Crédito em Cooperativas: Uma análise com base no perfil do cooperado. Sociedade, Contabilidade e Gestão, v. 7, n. 2, 2013.

FURTADO FILHO, L.F.; FLACH, L.; SALLABERRY, J. Mercado de capitais nos cenários de crise em mercados emergentes. GCG: revista de Globalización, Competitividad y Gobernabilidad, $\quad$ v. $13, \quad$ n. $3, \quad$ p. 83-96, $2019 . \quad$ Doi. https://doi.org/10.3232/GCG.2019.V13.N3.04.

GARCÍA, F.; GIMÉNEZ, V.; GUIJARRO, F. Credit risk management: A multicriteria approach to assess creditworthiness. Mathematical and computer modelling, v. 57, n. 7-8, p. 2009-2015, 2013. Doi. https://doi.org/10.1016/j.mcm.2012.03.005. 
GHÉDIRA, K. et al. Rule-based credit risk assessment model using multi-objective evolutionary algorithms. Expert Systems With Applications, v. 126, p. 144-157, 2019. Doi. https://doi.org/10.1016/j.eswa.2019.01.078.

GOLDSTEIN, I.; YANG, L. Good disclosure, bad disclosure. Journal of Financial Economics, v. 131, n. 1, p. 118-138, 2019. Doi. https://doi.org/10.1016/j.jineco.2018.08.004.

GOLDSTEIN, l; YANG, L. Information disclosure in financial markets. Annual Review of Financial Economics, v. 9, p. 101-125, 2017. Doi. https://doi.org/10.1146/annurevfinancial-110716-032355.

GUIMARÃES, I.C. et al. Evidenciação contábil: análise do nível de divulgação das demonstrações contábeis por empresas do Estado de Goiás. In: Anais do Congresso Brasileiro de Custos-ABC. 2005.

HAKENES, H.; SCHNABEL, I. Bank size and risk-taking under Basel II. Journal of Banking \& Finance, v. 35, n. 6, p. 1436-1449, 2011.

HAMADI, M. et al. Does Basel II affect the market valuation of discretionary loan loss provisions?. Journal of Banking \& Finance, v. 70, p. 177-192, 2016. Doi. http://dx.doi.org/10.1016/j.jbankfin.2016.06.002.

HEALY, P.M.; PALEPU, K.G. Information asymmetry, corporate disclosure, and the capital markets: A review of the empirical disclosure literature. Journal of accounting and economics, v. 31, n. 1-3, p. 405-440, 2001.

HEIN, N.; MAGRO, C.B.D.; MONDINI, V.E.D. Gestão dos riscos de inadimplência dos tomadores de crédito: Um estudo em uma cooperativa de crédito. Pensar Contábil, v. 17, n. 62, 2015. 
JIMENEZ, G.; SALAS, V.; SAURINA, J. Determinants of collateral. Journal of financial economics, v. $81, \quad$ n. 2 , p. 255-281, 2006. Doi. http://dx.doi.org/10.1016/j.jfineco.2005.06.003.

LAVARDA, C. et al. Incertezas Estratégicas e Riscos no Sistema de Controle Gerencial das Cooperativas de Crédito. Revista Eletrônica de Administração e Turismo-ReAT, v. 7, n. 4, p. 665-687. Doi. http://dx.doi.org/10.15210/reat.v7i4.5982.

MACHINSKI, P.A.; MOREIRA, V.R.; SILVA, R.A. Gestão do risco de crédito em cooperativas agroindustriais: um estudo de caso. Revista de Gestão e Organizações Cooperativas, v. 6, n. 12, p. 83-100, 2019. Doi. http://dx.doi.org/10.5902/2359043234611.

MÜLLER, F. M.; RIGHI, M. B. Model risk adjusted risk forecasting. Working Paper, 2018

MURCIA, F.D.; SANTOS, A. Principais práticas de disclosure voluntário das 100 maiores empresas listadas na Bolsa de Valores de São Paulo. Revista Contabilidade e Controladoria, v. 1, n. 1, 2009. Doi. http://dx.doi.org/10.5380/rcc.v1i1.14749.

NIEDERAUER, C.B.; VENDRUSCOLO, M.I.; SALLABERRY, J.. Análise das Demonstrações Contábeis: um estudo contemplando a emissão de ações no BANRISUL SA. Revista de Contabilidade da UFBA, v. 12, n. 3, p. 86-110, 2018. Doi. http://dx.doi.org/10.9771/rcufba.v12i3.21039.

NIYAMA, Jorge Katsumi; GOMES, Amaro L. Oliveira. Contabilidade de instituições financeiras. Atlas, 2002.

PONTE, V.M.R.; OLIVEIRA, M.C. A prática da evidenciação de informações avançadas e não obrigatórias nas demonstrações contábeis das empresas brasileiras. Revista 
Contabilidade \& Finanças, v. 15, n. 36, p. 7-20, 2004 . Doi. http://dx.doi.org/10.1590/S1519-70772004000300001.

PORFIRIO, L. V.; FERNANDES, B.V.R.; DANTAS, J. A.; Um retrato do cooperativismo de crédito no Brasil: perfil dos municípios brasileiros em dezembro de 2017. Revista de Gestão e Organizações Cooperativas, Vol. 6, n. 12, 2019, p. 201-218. Doi. http://dx.doi.org/10.5902/2359043235743.

SALLABERRY, J.; MEDEIROS, O.R. Os efeitos da crise financeira de 2008 no valor das empresas e nos ativos intangíveis. Revista Contemporânea de Contabilidade, v. 12, n. 27, p. 187-205, 2015. Doi. https://doi.org/10.5007/2175-8069.2015v12n27p187.

SALOTTI, B.M.; YAMAMOTO, M.M. Divulgação voluntária da demonstração dos fluxos de caixa no mercado de capitais brasileiro. Revista Contabilidade \& Finanças, v. 19, n. 48, p. 37-49, 2008. Doi. https://doi.org/10.1590/S1519-70772008000300004.

SAVIO, L.V.B.; BASSO, K. Desenvolvimento de Negócios Cooperativos: o Desafio da Principalidade. Revista de Gestão e Organizações Cooperativas, v. 6, n. 12, p. 115132, 2019. Doi. http://dx.doi.org/10.5902/2359043234822.

SILVA, J. P. Gestão e análise de risco de crédito . Editora Atlas, 2014.

SILVA, W.B.; FORGIARINI, D.I.; ALVES, C.N. Desafios para a expansão do SICOOB de Açailândia/MA. Revista de Gestão e Organizações Cooperativas, v. 6, n. 12, p. 153172, 2019. Doi. http://dx.doi.org/10.5902/2359043233409.

TORRES, M.C.; GALDI, F.C. Análise da aderência do disclosure da gestão de riscos pelas instituições financeiras à circular Bacen 3.477. Revista Contemporânea de Contabilidade, v. 10 , n. 21 , p. 137-158, 2013. Doi. https://doi.org/10.5007/21758069.2013v10n21p137. 
TRAPP, A.C.G.; CORRAR, L.J. Avaliação e gerenciamento do risco operacional no Brasil: análise de caso de uma instituição financeira de grande porte. Revista Contabilidade \& Finanças, v. 16, n. 37, p. 24-36, 2005.

WEBER, C.S. The effect of central bank transparency on exchange rate volatility. Journal of International Money and Finance, v. 95, p. 165-181, 2019. Doi. https://doi.org/10.1016/j.jimonfin.2019.04.002.

WILLUMSEN, P. et al. Value creation through project risk management. International Journal of Project Management, v. 37, n. 5, p. 731-749, 2019. Doi. https://doi.org/10.1016/j.ijproman.2019.01.007.

ZINS, A.; WEILL, L. Islamic banking and risk: The impact of Basel II. Economic Modelling, v. 64, p. 626-637, 2017. 
